\title{
Development and validation of a case-finding algorithm for neck and back pain in the Canadian Armed Forces using health administrative data
}

\author{
François L. Thériaulta ${ }^{\mathrm{a}}$ Diane $\mathrm{Lu}^{\mathrm{a}}$ and Robert A. Hawes ${ }^{\mathrm{a}}$
}

\begin{abstract}
Introduction: In military organizations, neck and back pain are a leading cause of clinical encounters, medical evacuations out of theatres of operations, and involuntary release from service. However, tools to efficiently and accurately study these conditions in Canadian Armed Forces (CAF) personnel are lacking, and little is known about their distribution across the Canadian military. Methods: We reviewed the medical charts of 691 randomly sampled CAF personnel, and determined whether these subjects had suffered from neck or back pain at any point during the 2016 calendar year. We then developed an algorithm to identify neck or back pain patients, using large clinical and administrative databases. The algorithm was then validated by comparing its output to the results of our medical chart review. Results: Of the 691 randomly sampled subjects, 190 (27\%) had experienced neck or back pain at some point during the 2016 calendar year, $43 \%$ of whom had experienced chronic pain (i.e. pain lasting for at least 90 consecutive days). Our final algorithm correctly identified $65 \%$ of all patients with past-year pain, and $80 \%$ of patients with past-year chronic pain. Overall, the algorithm's measures of diagnostic accuracy were as follows: $65 \%$ sensitivity, $97 \%$ specificity, $91 \%$ positive predictive value, and $88 \%$ negative predictive value. Discussion: We have developed an algorithm that can be used to identify neck and back pain in CAF personnel efficiently. This algorithm is a novel research and surveillance tool that could be used to provide the epidemiological data needed to guide future intervention and prevention efforts.
\end{abstract}

Key words: algorithm measures of diagnostic accuracy, back pain, Canadian Armed Forces (CAF) members, clinical and administrative databases, military personnel, neck pain, validation

\section{RÉSUMÉ}

Introduction : Dans les organisations militaires, les douleurs cervicales et dorsales sont l'une des principales causes de consultations cliniques, d'évacuations médicales hors des théâtres d’opérations et de la libération involontaire du service. Cependant, on ne possède pas d'outils pour étudier ces affections avec efficacité et précision au sein du personnel des Forces armées canadiennes (FAC) et on n'en connaît pas vraiment la distribution chez les militaires canadiens. Méthodologie : Les chercheurs ont examiné les dossiers médicaux de 691 membres du personnel des FAC sélectionnés au hasard et établi si ces sujets avaient souffert de douleurs cervicales ou dorsales au cours de l'année civile 2016. Ils ont ensuite créé un algorithme pour dépister les patients atteints de douleurs cervicales ou dorsales à l'aide de vastes bases de données cliniques et administratives. Pour valider cet algorithme, ils en ont comparé les résultats avec ceux de l'examen des dossiers médicaux. Résultats : Sur les 691 sujets sélectionnés au hasard, 190 (27\%) avaient souffert de douleurs cervicales ou dorsales pendant l'année civile 2016, dont 43 \% avaient éprouvé des douleurs chroniques (persistant pendant au moins 90 jours consécutifs). L'algorithme définitif a permis de dépister correctement $65 \%$ de tous les patients ayant éprouvé des douleurs et $80 \%$ de ceux ayant souffert de douleurs chroniques au cours de l'année précédente. Dans l'ensemble, les mesures diagnostiques de l'algorithme atteignaient le taux de précision suivant : sensibilité de $65 \%$, spécificité de $97 \%$, valeur prédictive positive de $91 \%$ et valeur prédictive négative de $88 \%$. Discussion : Les chercheurs ont mis au point un algorithme qui peut être utilisé pour dépister les douleurs cervicales et dorsales avec efficacité au sein du personnel des FAC. Cet algorithme est un nouvel outil de recherche et de surveillance qui pourrait fournir les données épidémiologiques nécessaires pour orienter les futurs efforts d'intervention et de prévention.

Mots-clés : membres du personnel des Forces armées canadiennes (FAC), douleur cervicale, douleur dorsale, personnel militaire, données cliniques et administratives sur la santé, validation, algorithme de recherche de cas

a Canadian Forces Health Services Group, Department of National Defence, Ottawa

Correspondence should be addressed to François L. Thériault at francois.theriault3@forces.gc.ca. 


\section{INTRODUCTION}

Neck pain and back pain are pervasive in adult populations. A recent systematic review suggests that $40 \%$ of adults worldwide suffer from back pain at some point in their lives, but lifetime prevalence estimates range from below $6 \%$ to over $66 \%$ in specific studies. ${ }^{1}$ Annual prevalence estimates of neck pain typically range between $15 \%-50 \% .^{2}$ In Canada, where 1 of 5 adults currently suffers from chronic pain, neck and back are cited as the primary anatomical site of pain by nearly $40 \%$ of chronic pain sufferers. ${ }^{3}$ Neck and back pain are now recognized as the leading cause of worldwide activity limitation and work absenteeism. ${ }^{4}$ In 2005 , the direct costs for treating neck and back pain in United States (US) adults were estimated at nearly $\$ 86$ billion, or $9 \%$ of total US medical expenditures. ${ }^{5}$ Yet, direct medical expenditures only amount to a fraction of the total costs associated with neck and back pain; the indirect costs of absenteeism and disablement account for an estimated $90 \%$ of the total economic burden associated with spinal problems. ${ }^{6}$

Neck and back pain are of particular concern to military organizations. In the US Armed Forces, back problems are the most frequently cited reason for clinical encounters, ${ }^{7}$ and are one of the leading causes of medical evacuations out of theatres of operations. ${ }^{8}$ In the Canadian Armed Forces (CAF), an estimated 16\% and $6 \%$ of personnel suffer from chronic back and neck problems, respectively, ${ }^{9}$ and low back pain alone is responsible for $12 \%$ of all medical releases in a given year. ${ }^{10}$ Moreover, recent evidence suggests that low back pain during military service predicts future back pain episodes later in life. ${ }^{11}$

Preventing neck and back pain is, therefore, a public health priority for military organizations. However, only limited cross-sectional evidence from anonymous population health surveys ${ }^{9}$ are available to inform neck and back pain prevention efforts across the CAF organization. Longitudinal data are needed to study the trajectories of neck and back pain over time, to better guide clinical care management and to identify new intervention opportunities. ${ }^{6,12,13} \mathrm{We}$ also need tools to more efficiently conduct cross-sectional neck and back pain surveillance across the CAF.

The CAF implemented an electronic medical record system in 2012. Since then, primary care physicians have electronically recorded their health assessments of CAF personnel using standardized diagnostic codes. The inclusion of one or more International
Classification of Disease $10^{\text {th }}$ revision (ICD-10) code is mandatory on all CAF primary care clinician notes, as a mechanism to summarize clinical diagnoses and patient concerns. These diagnostic codes can easily be extracted from electronic medical records and used for research and surveillance purposes. Neck and back pain surveillance could thus, in theory, be conducted across the CAF organization by deterministically linking relevant diagnoses recorded in the electronic medical files of personnel over time. Unfortunately, diagnostic codes extracted from electronic medical records usually lack the accuracy required for rigorous research and surveillance. ${ }^{14,15}$ It is now widely recognized that particular combinations of standardized diagnostic codes (i.e., case-finding algorithms) must be developed and validated before data extracted from electronic medical records can be used for research and surveillance purposes. ${ }^{16}$ In a recent survey, $87 \%$ of Veterans Health Administration researchers identified "lack of validation" as a barrier to conducting pain research with electronic health record databases. ${ }^{17}$

The objectives of our study were two-fold: (1) develop a case-finding algorithm to identify neck and back pain in CAF personnel using ICD-10 codes extracted from electronic medical records, and (2) validate the newly-developed algorithm by comparing its performance against a reference standard measure of neck and back pain.

\section{METHODS}

\section{Data sources}

The Master Patient Index (MPI) is an administrative database, generated using weekly updates from the CAF Human Resource Management System. It contains temporal data (e.g., dates of birth, enrolment, release, and death), demographic data (e.g., sex), and occupational data (e.g., military occupation, rank, and unit) for all individuals who were eligible to receive care through the Canadian Forces Health Services at any point since $2010 .{ }^{18}$

The Canadian Forces Health Information System (CFHIS) was implemented in 2012 and is used to capture medical and scheduling data at more than 80 CAF point-of-care sites around the world. ${ }^{18}$ This system allows a wide variety of health practitioners working in CAF clinics - including physicians, nurses, medical technicians, physician assistants, physiotherapists, social workers, and other specialists - to document patient-level information using a combination of 
free-text and standardized data elements. Diagnoses are documented in electronic clinical notes by primary care physicians using ICD-10 codes. Multiple ICD-10 codes can be recorded on each electronic clinical note. The system also allows hard copies of clinical notes to be digitized and scanned into the electronic medical records of CAF patients. ${ }^{18}$

\section{Chart extraction tool}

For our study, we conducted a manual review of a patient's entire medical chart (including detailed descriptions of treatments, diagnoses, and patient symptoms found in clinical notes, assessments, specialist referrals, and diagnostic imaging reports), which was used as a reference standard measure of neck and back pain status. We developed a chart review and extraction tool to ensure that patient charts would be reviewed systematically and according to a standardized protocol. Our chart extraction tool was based on previous work completed by US Department of Veterans Affairs researchers for a recent validation study of acute low back pain in their own patient population, ${ }^{19}$ and was developed with input from relevant CAF stakeholders. Two authors (FLT and DL) piloted a preliminary version of this tool on a random sample of 10 CAF medical charts before finalizing its design.

\section{Sample selection}

Based on conservative estimates from a recent populationbased survey, ${ }^{9}$ we assumed that $20 \%$ of all CAF Regular Force personnel had suffered from diagnosed neck or back pain at some point between January and December 2016. Furthermore, we expected that once developed, our algorithm would correctly identify $90 \%$ of patients with at least one neck or back pain episode in the past year. Using methods described elsewhere, ${ }^{20}$ we estimated that a sample size of 691 individuals would be required to measure our expected sensitivity, at a 95\% confidence level with a $5 \%$ margin of error.

CAF members serve as either Regular Force personnel or Reservists. Regular Force personnel are fulltime soldiers, and receive complete medical coverage from the Canadian Forces Health Services. On the other hand, Reservists are mostly part-time soldiers and are usually only eligible to receive care through the Canadian Forces Health Services for medical issues directly related to their military service. CFHIS records should, therefore, provide a more comprehensive record of the health service utilization of Regular Force personnel, but only a partial overview of Reservists' recent medical histories. We therefore restricted our analysis to Regular Force personnel. From the MPI, we randomly sampled 691 individuals who had served in the Regular Force continuously from September 2015 to January 2017. Personnel posted to the Canadian Forces Health Services Group Headquarters in Ottawa were excluded from the sample, to prevent investigators from inadvertently accessing the confidential medical information of colleagues or acquaintances.

\section{Reference standard measure of neck and back pain}

The full electronic medical charts of all 691 randomly sampled individuals were manually reviewed by FLT (an epidemiologist with 4 years of research experience using CAF medical records), using the chart extraction tool described above. More specifically, we reviewed any document that was created between September 2015 and January 2017 and recorded in CFHIS as either a scanned image or an electronic note by a primary care clinician, physiotherapist, chiropractor, osteopath, neurologist, neurosurgeon, orthopaedic surgeon, anesthesiologist, physiatrist, sport medicine practitioner, or any other musculoskeletal pain specialist. We also reviewed diagnostic imaging reports for any spine segment recorded in CFHIS over the same period. Based on this review, the chart abstractor (FLT) determined whether each subject had suffered from neck or back pain at any point during each of the 12 calendar months, from January to December 2016. In accordance with previous studies, pain was categorized as affecting the neck (cervical spine), mid-back (thoracic spine), or low back (lumbar and sacral spine, including the coccyx), and was considered chronic if it persisted for at least 3 consecutive months. ${ }^{6,21}$

A random sub-sample of 30 medical charts were independently reviewed by DL (a medical epidemiologist, and practicing family physician at a CAF primary care clinic), for quality assurance purposes. In the sub-sample of 30 charts reviewed by both chart abstractors, inter-rater agreement was 93\%, and disagreements were resolved through discussion. DL also reviewed the medical charts of complex patients for whom pain status could not be clearly ascertained by FLT.

\section{Algorithm development}

A recent systematic review identified 150 different diagnostic codes that have been used by previous researchers to study neck or back pain with health administrative data. $^{21}$ We converted these codes to their ICD-10 
equivalents and removed duplicates. We identified other diagnostic codes potentially related to neck or back pain by reviewing the ICD-10 dictionary. ${ }^{22}$ Thus, we assembled a list of codes that we classified as representing either confirmed chronic disorders (e.g., spondylolisthesis, cervical disc disorder) or symptoms and injuries (e.g., dorsalgia, lumbar sprain) (Table 1).
We developed several algorithms (Table 2) by testing various combinations of the ICD-10 codes just described. In our final case-finding algorithm (i.e., algorithm G, Table 2), ICD-10 codes were grouped into neck and/or back pain episodes as follows. A pain-related ICD-10 code recorded after at least 180 days with no previous symptom or injury code, and

Table 1. List of ICD-10 codes used to identify neck and back pain

\begin{tabular}{|c|c|c|}
\hline ICD-10 code & ICD-10 label & Type \\
\hline M40.x & Kyphosis and lordosis & Chronic \\
\hline M41.x & Scoliosis & Chronic \\
\hline M43.0 & Spondylolysis & Chronic \\
\hline M43.1 & Spondylolisthesis & Chronic \\
\hline M43.2 & Fusion of spine & Chronic \\
\hline M43.6 & Torticollis & Symptom/injury \\
\hline M43.9 & Deforming dorsopathy, unspecified & Chronic \\
\hline M45.x & Ankylosing spondylitis & Chronic \\
\hline M46.x & Other inflammatory spondylopathies & Chronic \\
\hline M47.x & Spondylosis & Chronic \\
\hline M48.x & Other spondylopathies & Chronic \\
\hline M49.8 & Spondylopathies in diseases classified elsewhere & Chronic \\
\hline M50.x & Cervical disc disorders & Chronic \\
\hline M51.x & Thoracic, thoracolumbar, and lumbosacral disc disorders & Chronic \\
\hline M53.x & Other unspecified dorsopathies, not elsewhere classified & Chronic \\
\hline M54.x & Dorsalgia & Symptom/injury \\
\hline M95.3 & Acquired deformity of neck & Chronic \\
\hline M96.1 & Post-laminectomy syndrome, not elsewhere classified & Chronic \\
\hline M96.3 & Post-laminectomy kyphosis & Chronic \\
\hline M96.4 & Post-surgical lordosis & Chronic \\
\hline M96.5 & Post-radiation scoliosis & Chronic \\
\hline S12.x & Fracture of cervical vertebra and other parts of neck & Symptom/injury \\
\hline S13.x & Dislocation and sprain of joints and ligaments at neck level & Symptom/injury \\
\hline S22.0 & Fracture of thoracic vertebra & Symptom/injury \\
\hline S22.1 & Multiple fractures of thoracic vertebrae & Symptom/injury \\
\hline S23.0 & Traumatic rupture of thoracic vertebrae & Symptom/injury \\
\hline S23.1 & Subluxation and dislocation of thoracic vertebra & Symptom/injury \\
\hline S23.3 & Sprain of ligaments of thoracic spine & Symptom/injury \\
\hline S32.0 & Fracture of lumbar vertebra & Symptom/injury \\
\hline S32.1 & Fracture of sacrum & Symptom/injury \\
\hline S32.2 & Fracture of coccyx & Symptom/injury \\
\hline S32.7 & Multiple fractures of lumbar vertebrae & Symptom/injury \\
\hline S32.9 & Fracture of other and unspecified parts of lumbar spine & Symptom/injury \\
\hline S33.0 & Traumatic rupture of lumbar intervertebral disc & Symptom/injury \\
\hline
\end{tabular}

(Continued) 


\begin{tabular}{lll}
\hline ICD-10 code & \multicolumn{1}{c}{ ICD-10 label } & Type \\
\hline S33.1 & Subluxation and dislocation of lumber intervertebral disc & Symptom/injury \\
S33.3 & Dislocation of other and unspecified part of lumbar spine & Symptom/injury \\
S33.5 & Sprain of ligaments of lumbar spine & Symptom/injury \\
S33.7 & Sprain and strain of other and unspecified part of lumbar spine & Symptom/injury \\
\hline
\end{tabular}

Note: Each algorithm is identified by a unique letter (see Table 2).

ICD = International Classification of Disease

Table 2. Algorithms developed to identify patients with neck or back pain during study period

\begin{tabular}{ll}
\hline Algorithm & \multicolumn{1}{c}{ Case definition } \\
\hline A & $\geq 1$ ICD-10 code for neck or back pain recorded during study period \\
C & $\geq 2$ ICD-10 codes for neck or back pain recorded during study period \\
& $\geq 1$ ICD-10 code for chronic neck or back pain, or $\geq 2$ ICD-10 codes for neck or back symptoms/injury \\
recorded during study period & $\geq 1$ day during study period where patient met following criteria: $\geq 1$ ICD-10 code for neck or back pain \\
& recorded during previous 365 days \\
& $\geq 1$ day during study period where patient met following criteria: $\geq 1$ ICD-10 code for chronic neck or back \\
& pain recorded during previous 365 days, or $\geq 1$ ICD-10 code for neck or back symptoms/injury during \\
& previous 180 days \\
& $\geq 1$ day during study period where patient had active episode of neck or back pain. All ICD-10 codes for \\
& chronic neck or back pain recorded within 365 days of each other were linked into a single episode; all \\
& ICD-10 codes for neck or back symptom/injury recorded within 180 days of any ICD-10 code for neck or \\
& back pain were also linked. Episodes start 7 days before the date of first diagnosis, and end 45 days after \\
& the date of the last diagnosis. \\
& $\geq 1$ day during study period where patient had active episode of neck or back pain. All ICD-10 codes for \\
chronic neck or back pain recorded within 365 days of each other were linked into a single episode; all \\
ICD-10 codes for neck or back symptom/injury recorded within 180 days of any ICD-10 code for neck or \\
back pain were also linked. Episodes containing at least one ICD-10 code for chronic neck or back pain \\
start 30 days before date of first diagnosis, and end 180 days after the date of the last diagnosis; episodes \\
containing only symptom/injury codes start 7 days before the date of first diagnosis, and end 7 days after \\
the date of the last diagnosis.
\end{tabular}

ICD = International Classification of Disease

365 days with no previous chronic disorder code, was interpreted as the first data signal of a given pain episode. Similarly, a symptom or injury code followed by at least 180 days with no further pain-related ICD-10 code, or a chronic disorder code followed by at least 365 days with no further pain-related ICD-10 code, was interpreted as the last data signal of a given pain episode. If an episode contained at least one chronic disorder code, we assumed the patient experienced pain onset 30 days before its first data signal, and pain remission 180 days after its last data signal. If an episode contained only symptom and injury codes, we assumed the patient experienced pain onset 7 days before its first data signal, and pain remission 7 days after its last data signal.

\section{Statistical analysis}

We applied our case-finding algorithm to the sample of 691 randomly-selected subjects to estimate which patients had suffered from neck or back pain at any point from January to December 2016. We validated each case-finding algorithm by comparing its classification of past-year pain status in study subjects to the reference standard measure (i.e., past-year pain status ascertained through detailed medical chart review). We then estimated the sensitivity, specificity, and predictive values. We selected the algorithm with the greatest area under the receiver operating characteristic ( $\mathrm{ROC}$ ) curve as our final case-finding algorithm.

We repeated the analysis described above to estimate the diagnostic accuracy of our final case-finding 
algorithm at a monthly time scale. We therefore compared past-month pain status ascertained using the final case-finding algorithm versus the reference standard for each calendar month, from January to December 2016.

\section{Ethical considerations}

All data were stored on a secured computer network available only to authorized epidemiologists within the Canadian Forces Health Services Group Headquarters. The study was conducted in accordance with the Population and Occupational Health Directive issued by the CAF Privacy Officer and was approved by the CAF Director of Force Health Protection.

\section{RESULTS}

Study subjects were $86.1 \%$ male, $71.2 \%$ under the age of 40 years, and $74.7 \%$ non-officer, which is representative of the total Regular Force population from which they were sampled (Table 3).

Chart reviews identified at least one pain episode in 190 of 691 study subjects. According to our reference standard measurement, 27.5\% (95\% CI, 24.3\%-31.0\%) of our sample therefore suffered from documented neck or back pain at some point during the study period. The low back was the spinal segment from which pain most frequently originated, affecting $72.1 \%$ (95\% CI, 65.2\%$78.4 \%$ ) of all past-year neck and back pain patients. Furthermore, $11.9 \%$ (95\% CI, 9.6\%-14.5\%) of the entire sample, or $43.2 \%$ (95\% CI, 36.0\%-50.5\%) of the 190 patients with past-year pain, had chronic pain (Table 4)

Table 3. Demographic characteristics of the study sample and the Regular Force population

\begin{tabular}{lccccc}
\hline Variable & \multicolumn{2}{c}{ Study sample } & & \multicolumn{2}{c}{ Regular Force } \\
& $n$ & $(\%)$ & & & $(\%)$ \\
\hline Sex & & & & \\
$\quad$ Female & 96 & $(13.9)$ & & 9,420 & $(14.3)$ \\
$\quad$ Male & 595 & $(86.1)$ & & 56,260 & $(85.7)$ \\
Age (years) & & & & \\
18-29 & 234 & $(33.8)$ & & 21,694 & $(33.0)$ \\
$30-39$ & 258 & $(37.3)$ & & 22,628 & $(34.5)$ \\
$40-49$ & 143 & $(20.7)$ & 14,653 & $(22.3)$ \\
$50-60$ & 56 & $(8.1)$ & 6,705 & $(10.2)$ \\
Officer & & & & \\
No & 516 & $(74.7)$ & 49,639 & $(75.6)$ \\
Yes & 175 & $(25.3)$ & 16,041 & $(24.4)$ \\
\hline
\end{tabular}

Our final algorithm (algorithm G, Figure 1) identified at least one episode in $65.3 \%$ of patients who truly had any type of neck or back pain at some point in 2016, and in $80.5 \%$ of patients who had chronic pain over the same period (Table 4). It should be noted that, of the 66 false-negative patients, only 16 (24.2\%) had experienced chronic pain (Table 4). When used to estimate the annual prevalence of any neck or back pain, the algorithm had $65.3 \%$ sensitivity, $97.4 \%$ specificity, $90.5 \%$ positive predictive value, and $88.1 \%$ negative predictive value (Table 5). The algorithm correctly classified the pastyear pain status of $612(88.6 \%)$ study subjects, when compared to the reference standard (Table 4).

Over the study period, the reference standard measurement revealed a monthly prevalence of neck and back pain ranging from $11.0 \%$ to $13.0 \%$ in our sample of 691 subjects. For any month between January and December 2016, the algorithm correctly identified 40.5\% to $59.7 \%$ of patients who truly had neck or back pain during that particular month. When used to estimate the monthly prevalence of neck or back pain, the algorithm had, on average, $48.0 \%$ sensitivity, $98.6 \%$ specificity, $82.5 \%$ positive predictive value, and $93.3 \%$ negative predictive value (Table 5)

\section{DISCUSSION}

We successfully completed a full medical chart review in a representative sample of CAF Regular Force personnel. In doing so, we uncovered a $27.5 \%$ annual

Table 4. Number of CAF Regular Force personnel with past-year neck or back pain, as ascertained using a reference standard, and as estimated using a case-finding algorithm

\begin{tabular}{lccc}
\hline Reference standard & Total & \multicolumn{2}{c}{$\begin{array}{c}\text { Algorithm identified } \\
\text { past-year neck or back } \\
\text { pain }\end{array}$} \\
\cline { 3 - 4 } & & No & Yes \\
\hline No pain & 501 & 488 & 13 \\
Any neck or back pain & 190 & 66 & 124 \\
Pain duration & & & \\
$\quad$ Acute/sub-acute pain & 108 & 50 & 58 \\
$\quad$ Chronic pain & 82 & 16 & 66 \\
Pain location & & & \\
$\quad$ Neck pain & 48 & 18 & 30 \\
$\quad$ Mid-back pain & 32 & 16 & 16 \\
Low back pain & 137 & 38 & 99 \\
\hline
\end{tabular}




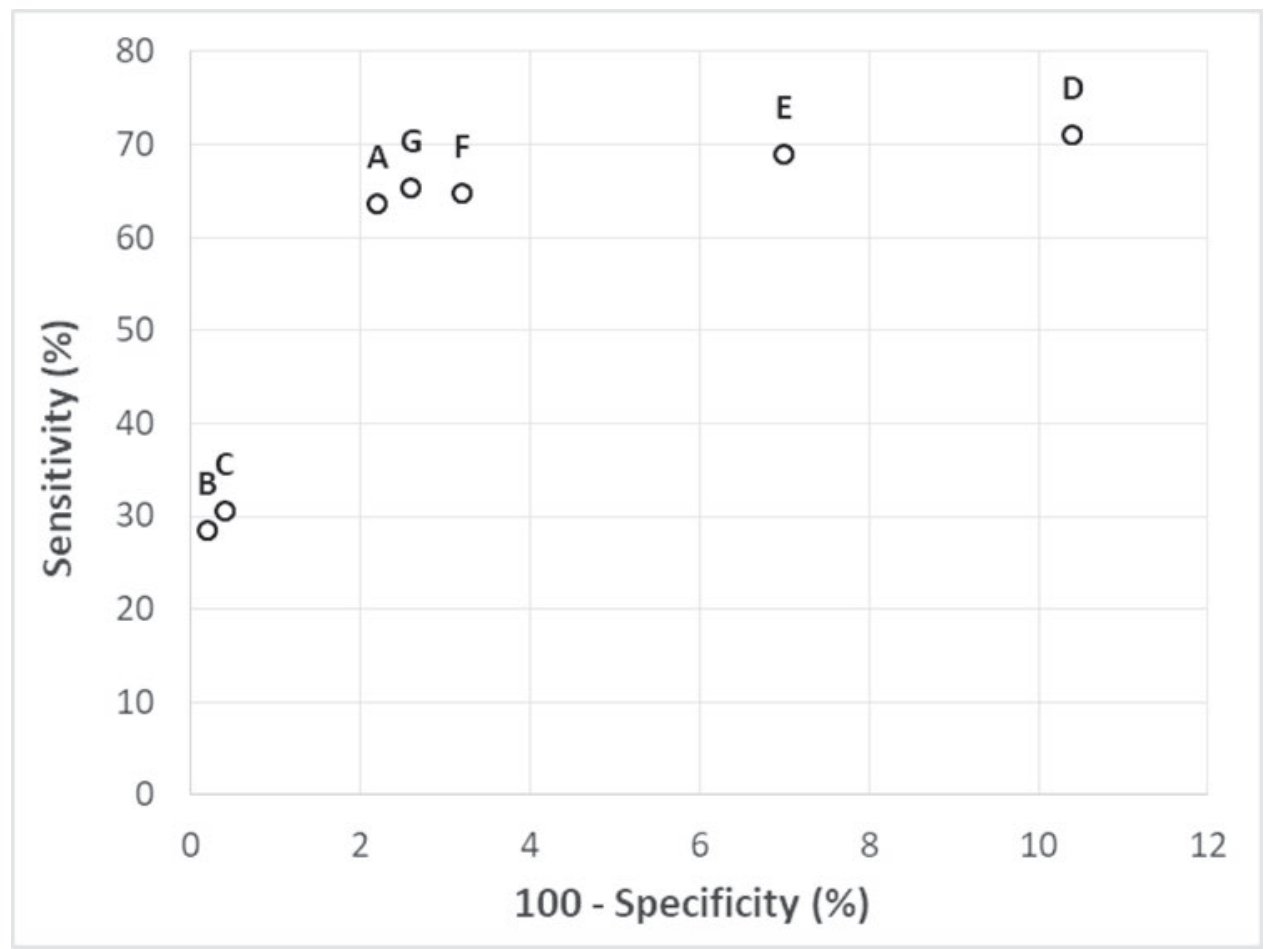

Figure 1. Sensitivity and specificity of case-finding algorithms for identifying past-year neck or back pain in a sample of 691 CAF Regular Force personnel

Table 5. Diagnostic accuracy of a case-finding algorithm, when used to measure annual and monthly prevalence of neck or back pain in CAF Regular Force personnel

\begin{tabular}{lcc}
\hline Measure of diagnostic & \multicolumn{2}{c}{ Look-back period } \\
\cline { 2 - 3 } accuracy & Past-year & Past-month* \\
\hline Sensitivity $(95 \% \mathrm{Cl})$ & $65.3(58.2,71.7)$ & $48.0(37.3,58.9)$ \\
Specificity $(95 \% \mathrm{Cl})$ & $97.4(95.6,98.5)$ & $98.6(97.3,99.3)$ \\
Positive predictive & $90.5(84.5,94.4)$ & $82.5(68.5,91.0)$ \\
value (95\% Cl) & & \\
$\begin{array}{l}\text { Negative predictive } \\
\text { value (95\% Cl) }\end{array}$ & $88.1(85.1,90.5)$ & $93.3(91.1,95.0)$ \\
\hline
\end{tabular}

* Measures of diagnostic accuracy averaged over the 12 calendar months in 2016

prevalence of neck and back pain and provided one of the most detailed reports to date on neck and back pain epidemiology in the Canadian military. We also developed and validated a case-finding algorithm that replicated the outcomes of our full medical chart review, with adequate diagnostic accuracy.

The high annual prevalence reported herein is consistent with findings of previous Canadian military surveys, ${ }^{9}$ and highlights the public health importance of neck and back pain in the CAF. Other military organizations have also found high prevalence and incidence of back pain in their respective populations: using data extracted from electronic health records, the US Armed Forces reported 40.5 new cases of low back pain per 1,000 person-years at risk; ${ }^{23}$ in the Australian Defence Force, neck and back pain accounted for $54 \%$ of all cases treated in physiotherapy over a 2 -year period; $;^{24}$ and $11 \%$ of Swedish conscripts had back pain-related ICD10 codes entered in their clinical records at the time of their recruitment medical exam. ${ }^{25}$

Our case-finding algorithm correctly classified the past-year pain status of $88.6 \%$ of sample subjects. It had moderate sensitivity (65.3\%), but very high specificity (97.4\%). Similarly, previous studies have shown that ICD codes extracted from physician billing databases can identify chronic neck and back pain cases among Quebec residents with $71 \%$ sensitivity and $78 \%$ specificity. ${ }^{26}$ The diagnostic accuracy of our algorithm is also comparable to that of other algorithms developed to study low back pain in US Veterans (82\% concordance) $)^{19}$ and severe sepsis in Canadian in-patients $(65 \%$ sensitivity, $88 \%$ specificity), ${ }^{27}$ and is higher than most 
algorithms developed to study depression in general adult populations $\left(28 \%-35 \%\right.$ sensitivity). ${ }^{28}$

Our case-finding algorithm identified past-year pain with greater diagnostic accuracy in patients who had suffered from chronic pain, compared to patients with only acute and self-limiting pain episodes. This result is not surprising, and reflects a well-described limitation of large clinical databases: at the population level, severely sick and injured individuals are described in much greater detail than their healthier counterparts. ${ }^{15}$ Indeed, chronic pain patients tended to have more frequent interactions with health care providers, and over longer periods of time, compared to patients with self-limiting pain episodes. Each of these clinical interactions provided an additional opportunity for data capture. The algorithm missed $35 \%$ of patients with past-year pain, but $75 \%$ of false-negative cases had only suffered from a self-limiting pain episode lasting less than 3 months and did not have a single pain-related ICD-10 code recorded in their electronic medical charts over the study period. Some health care providers (e.g., nurses, physiotherapists, and medical technicians) do not have the professional authority to assign formal diagnoses; they may, therefore, treat neck and back patients but record the care provided as free-text notes in their patients' electronic medical charts.

Furthermore, physiotherapists providing care to neck and back pain patients at specialized CAF clinics still record their diagnoses on paper documents, which are subsequently scanned into patients' electronic medical charts. Over the course of several months of treatment, chronic pain patients are likely to eventually interact with a clinician who has access to CFHIS, and who will record a pain-related ICD-10 code in their electronic medical charts. In contrast, patients with pain episodes of short duration have a lower likelihood of having ICD-10 codes recorded in their electronic medical charts, and being subsequently missed by an ICD-10-based case-finding algorithm.

It is also worth noting that our final case-finding algorithm provided more accurate estimates of annual prevalence than monthly prevalence. This finding highlights another well-described limitation of clinical data: diagnostic codes are cross-sectional in nature, and cannot be used to pinpoint the dates of pain onset and remission. ${ }^{29}$ Indeed, patients sometimes only seek care several months after the sudden onset of neck or back pain. ${ }^{30}$ Moreover, patients who achieve pain remission are likely to simply stop attending treatment, rather than contact a health care provider to report being painfree. ${ }^{29}$ Our detailed medical chart review revealed that approximate onset and remission dates were sometimes recorded after the fact, in a free-text report, as part of periodic and mandatory health assessments. For example, CAF clinicians completing routine health assessments may document that their patients suffered from acute low back pain earlier in the year, but have now been pain-free for the last 2 months. These patients may have sought care once or twice for their pain, but may not have generated ICD-10 codes to mark the beginning and end of their acute pain episodes. In such cases, ICD-10 codes clearly indicated that patients suffered from neck or back pain at some point during the 1-year study period, but the dates of pain onset and remission remained unclear. Our case-finding algorithm thus generated substantial misclassification of pain status near the beginning and end of acute pain episodes. For this reason, our algorithm should be used for neck and back pain surveillance on yearly, rather than monthly, time scales.

Our study had noteworthy limitations. First, our reference standard definition of neck or back pain status was not a true "gold standard" measurement, insofar as detailed medical chart reviews may not identify all cases of neck or back pain. Indeed, medical charts can only identify patients who sought medical care for their pain. However, a large population-based survey found that nearly 20\% of CAF Regular Force personnel with activity-limiting back injuries do not seek professional care. ${ }^{9}$ Similarly, a meta-analysis of population-based surveys from around the world has previously shown that only $58 \%$ of adults with low back pain seek medical care ${ }^{31}$ the remaining $42 \%$ would, therefore, have no pain-related information in their clinical records. Our reference standard may therefore have missed several true cases, and our case-finding algorithm may consequently not be as accurate as reported herein. Second, our final case-finding algorithm missed over one-third of care-seeking pain patients. Comparably low sensitivities have been reported by researchers studying neck and back pain in other populations, ${ }^{26}$ and may be explained by the limited access to ICD-10 coding functionality across $\mathrm{CAF}$ health care providers. Generally speaking, only physicians can enter ICD-10 diagnostic codes in the electronic medical records of patients. Other health care professionals - including physiotherapists, medical technicians, and civilian pain specialists - often treat CAF personnel for neck 
or back pain, but document all the care provided to their patients in digitally scanned formats that are difficult to extract from CAF electronic medical records. The majority of false-negative cases included in our sample had generated no ICD-10 codes during the study period for this very reason, and would therefore have been missed by any ICD-based algorithm, regardless of its sophistication.

It should be noted that the limitations described above can be largely mitigated using previously proposed bias correction methods. ${ }^{32}$ Having rigorously quantified our algorithm's tendency to misclassify certain individuals, we can now incorporate our reported measures of diagnostic accuracy in bias-adjustment formulas, ${ }^{32}$ and correct our estimates of neck and back pain prevalence for misclassification. Our validated case-finding algorithm could thus be used to provide highly accurate estimates of annual neck and back pain prevalence across the CAF population, despite its $65 \%$ sensitivity and $97 \%$ specificity.

In conclusion, we have developed and validated a case-finding algorithm that can henceforth be used to conduct neck and back pain surveillance in CAF personnel efficiently. This marks an important achievement for public health surveillance in the CAF. In military organizations, neck and back pain are a leading cause of morbidity and health care-associated costs, and a serious impediment to operational readiness. A new tool to study the prevalence and distribution of these disorders across the CAF organization is now available. Our case-finding algorithm will help future researchers provide the evidence needed to better inform clinical resource allocation and prevention efforts related to neck and back pain.

\section{REFERENCES}

1. Hoy D, Bain C, Williams G, et al. A systematic review of the global prevalence of low back pain. Arthritis Rheum. 2012;64(6):2028-37. https://doi. org/10.1002/art.34347. Medline:22231424

2. Cohen SP. Epidemiology, diagnosis, and treatment of neck pain. Mayo Clin Proc. 2015;90(2):284-99. https://doi. org/10.1016/j.mayocp.2014.09.008. Medline:25659245

3. Schopflocher D, Taenzer P, Jovey R. The prevalence of chronic pain in Canada. Pain Res Manag. 2011;16(6):445-50. https://doi. org/10.1155/2011/876306. Medline:22184555

4. Hoy D, Brooks P, Blyth F, et al. The epidemiology of low back pain. Best Pract Res Clin Rheumatol. 2010;24(6):769-81. https://doi.org/10.1016/j. berh.2010.10.002. Medline:21665125
5. Martin BI, Deyo RA, Mirza SK, et al. Expenditures and health status among adults with back and neck problems. JAMA. 2008;299(6):656-64. https://doi. org/10.1001/jama.299.6.656. Medline:18270354

6. van Tulder M, Koes B, Bombardier C. Low back pain. Best Pract Res Clin Rheumatol. 2002;16(5):761-75. https://doi.org/10.1053/berh.2002.0267. Medline: 12473272

7. Clark LL, Hu Z. Diagnoses of low back pain, active component, U.S. Armed Forces, 2010-2014. MSMR. 2015;22(12): 8-11. Medline:26726722

8. Armed Forces Health Surveillance Center (AFHSC). Medical evacuations from Operation Iraqi Freedom/ Operation New Dawn, active and reserve components, U.S. Armed Forces, 2003-2011. MSMR. 2012;19(2): 18-21. Medline:22372753

9. Thériault FL, Gabler K, Naicker K. Health and Lifestyle Information Survey of Canadian Armed Forces Personnel 2013/2014 - Regular Force Report. In: Strauss BA, Whitehead J, editors. Ottawa: Department of National Defence; 2016.

10. Canadian Forces Health Services Group. Surgeon General's Integrated Health Strategy - 2017. Ottawa: Department of National Defence; 2017.

11. Mattila VM, Kyröläinen H, Santtila M, et al. Low back pain during military service predicts low back pain later in life. PLoS One. 2017;12(3):e0173568. https://doi.org/10.1371/journal.pone.0173568. Medline:28282419

12. Axen I, Lebeouf-Yde C. Trajectories of low back pain. Best Pract Res Clin Rheumatol. 2013;27(5):601-12. https://doi.org/10.1016/j.berh.2013.10.004. Medline:24315142

13. Kongsted A, Kent P, Axen I, et al. What have we learned from ten years of trajectory research in low back pain? BMC Musculoskelet Disord. 2016;17(1):220. https://doi.org/10.1186/s12891-016-1071-2. Medline:27209166

14. Benchimol EI, Manuel DG, To T, et al. Development and use of reporting guidelines for assessing the quality of validation studies of health administrative data. J Clin Epidemiol. 2011;64(8):821-9. https:// doi.org/10.1016/j.jclinepi.2010.10.006. Medline:21194889

15. Deeny SR, Steventon A. Making sense of the shadows: priorities for creating a learning healthcare system based on routinely collected data. BMJ Qual Saf. 2015;24(8):505-15. https://doi.org/10.1136/bmjqs-2015-004278. Medline:26065466

16. Benchimol EI, Smeeth L, Guttmann A, et al. The reporting of studies conducted using observational routinely-collected health data (RECORD) statement. PLoS Med. 2015;12(10):e1001885. https:// 
doi.org/10.1371/journal.pmed.1001885. Medline: 26440803

17. Abel EA, Brandt CA, Czlapinski R, et al. Pain research using Veterans Heath Administration electronic and administrative data sources. J Rehabil Res Dev. 2016;53(1):1-12. https://doi.org/10.1682/ jrrd.2014.10.0246. Medline:27005814

18. Hawes RA, Thériault FL, Bogaert LE. Military health informatics to improve deployed and in-garrison health surveillance: epidemiologic evidence from the Canadian Armed Forces Health Information System. Report MP-HFM-254-31. NATO Science and Technology Organization; 2015. Available from: https://www.sto. nato.int/publications.

19. Lisi AJ, Burgo-Black AL, Kawecki T, et al. Use of Department of Veterans Affairs administrative data to identify Veterans with acute low back pain: a pilot study. Spine. 2014;39(14):1151-6. https://doi.org/10.1097/ brs. 0000000000000350 . Medline:24732845

20. Buderer NM. Statistical methodology: I. Incorporating the prevalence of disease into the sample size calculation for sensitivity and specificity. Acad Emerg Med. 1996;3(9):895-900. https://doi. org/10.1111/j.1553-2712.1996.tb03538.x. Medline: 8870764

21. Sinnott PL, Siroka AM, Shane AC, et al. Identifying neck and back pain in administrative data: defining the right cohort. Spine. 2012;37(10):860-74. https:// doi.org/10.1097/brs.0b013e3182376508. Medline: 22127268

22. World Health Organization. International statistical classification of diseases and related health problems. 10th revision, 5th ed. Geneva, Switzerland: WHO; 2016.

23. Knox J, Orchowski J, Scher DL, et al. The incidence of low back pain in active duty United States military service members. Spine. 2011;36(18):1492-500. https://doi.org/10.1097/brs.0b013e3181f40ddd. Medline:21224777

24. Sellentin R, Sanchez P. Review of physiotherapy records to characterise musculoskeletal injury in Australian soldiers in the 16th Air Defence Regiment. J Mil Veterans Health. 2011;19(4):6-12.

25. Leboeuf-Yde C, Larsen K, Ahlstrand I, et al. Coping and back problems: analysis of multiple data sources on an entire cross-sectional cohort of Swedish military recruits. BMC Musculoskelet Disord. 2006;7(1):39. https://doi.org/10.1186/1471-2474-7-39. Medline: 16672044

26. Lacasse A, Ware MA, Dorais M, et al. Is the Quebec provincial administrative database a valid source for research on chronic non-cancer pain? Pharmacoepidemiol Drug Saf. 2015;24(9):980-90. https://doi. org/10.1002/pds.3820. Medline:26105572
27. Jolley RJ, Quan H, Jetté N, et al. Validation and optimisation of ICD-10-coded case definition for sepsis using administrative health data. BMJ Open. 2015;5(12):e009487. https://doi.org/10.1136/ bmjopen-2015-009487. Medline:26700284

28. Fiest KM, Jette N, Quan H, et al. Systematic review and assessment of validated case definitions for depression in administrative data. BMC Psychiatry. 2014;14:289. https://doi.org/10.1186/s12888-014-0289-5. Medline: 25322690

29. Roy J, Stewart WF. Methods for estimating remission rates from cross-sectional survey data: application and validation using data from a national migraine study. Am J Epidemiol. 2011;173(8):949-55. https://doi. org/10.1093/aje/kwq464. Medline:21357656

30. Woodhouse A, Pape K, Romunstad PR, et al. Health care contact following a new incident neck or low back pain episode in the general population; the HUNT study. BMC Health Serv Res. 2016;16(1):81. https://doi.org/10.1186/s12913-016-1326-5. Medline:26955969

31. Ferreira ML, Machado G, Latimer J, et al. Factors defining care-seeking in low back pain: a meta-analysis of population based surveys. Eur J Pain. 2010;14(7):747. e1-7. https://doi.org/10.1016/j.ejpain.2009.11.005. Medline:20036168

32. Lash TL, Fox MP, Fink AK. Applying quantitative bias analysis to epidemiologic data. New York: Springer-Verlag; 2009. 192 p.

\section{AUTHOR INFORMATION}

François Thériault, MSc, is an epidemiologist in the Directorate of Force Health Protection, Canadian Forces Health Services Group. He is also completing a $\mathrm{PhD}$ in Epidemiology at the University of Ottawa.

Diane Lu, MD, PhD, MPH, is a medical epidemiologist, and the head of the Epidemiology section in the Directorate of Force Health Protection, Canadian Forces Health Services Group. She is responsible for the population health surveillance of Canadian Armed Forces personnel, from recruitment to post-release.

Robert Hawes, MSc, is a senior epidemiologist in the Directorate of Force Health Protection, Canadian Forces Health Services Group. He is responsible for the design and implementation of the Canadian Forces Health, Evaluations and Reporting Outcomes (CF-HERO) system and coordinates the population-level analyses of enlisted Canadian Armed Forces personnel.

\section{COMPETING INTERESTS}

None declared.

This article has been peer reviewed. 


\section{CONTRIBUTORS}

FLT and RAH conceived and designed the study. All authors contributed to data acquisition. FLT and DL reviewed medical charts. FLT analyzed the data and drafted the manuscript. RAH and DL edited and revised the manuscript. All authors approved the final version submitted for publication.

\section{FUNDING}

None declared.

\section{ACKNOWLEDGEMENTS}

The authors wish to thank Dr. Anthony Lisi for his help in designing the chart extraction tool. 